\title{
Improvisação organizacional: desafios e perspectivas para o ensino-aprendizagem em administração
}

\author{
Fernanda Paquelet Moreira Barbosa ${ }^{1}$ \\ EDUARDO DAVEL ${ }^{1}$ \\ ${ }^{1}$ Universidade Federal da Bahia (UFBA) / Escola de AdMINISTRAÇÃo, SALVAdor - BA, BrasiL
}

\section{Resumo}

A improvisação organizacional é pesquisada há mais de 30 anos, pois ressalta a importância de sofisticar a prática de gestores e líderes frente às imprevisibilidades cada vez mais marcadas na contemporaneidade. Carecemos de uma visão mais atualizada da produção em improvisação organizacional e de uma reflexão sobre de que modo integrá-la na formação do gestor. O objetivo desta pesquisa é sistematizar os avanços na produção acadêmica acerca de improvisação organizacional e discutir sua integração no ensino-aprendizagem da administração. A metodologia de pesquisa consiste num levantamento sistemático da produção acadêmica. Os resultados da pesquisa fornecem um conjunto atualizado de relevâncias e temáticas relacionadas à improvisação organizacional, uma discussão sobre a importância da improvisação organizacional para a pesquisa em ensino-aprendizagem em administração e um conjunto de abordagens educacionais, barreiras e perspectivas que ajudam pesquisas e práticas futuras a melhor integrar a improvisação no ensino-aprendizagem em administração. A principal contribuição deste estudo é inaugurar uma nova orientação de pesquisa: o ensino-aprendizagem da improvisação organizacional.

Palavras-chave: Improvisação organizacional. Ensino-aprendizagem. Ensino da improvisação. Desafios do ensino.

\section{Organizational improvisation: challenges and perspectives for management education}

\begin{abstract}
Organizational improvisation has been researched for over 30 years as it emphasizes the importance of improving the practice of managers and leaders dealing with unpredictability, increasingly stressed in contemporary times. An updated view of academic production in organizational improvisation is necessary, and a reflection on integrating it in management education. This research aims to systematize the advances in academic production on organizational improvisation and discuss its integration in management education. The research methodology consists of a systematic survey of academic production. The research results include: (a) a set of actual relevances and themes related to organizational improvisation, (b) a discussion about the importance of organizational improvisation for management education research, and (c) a set of educational approaches, barriers, and perspectives that help research and future practices to better integrate improvisation in management teaching and learning. The main contribution of this research is to inaugurate a new research orientation: the teachinglearning of organizational improvisation.
\end{abstract}

Keywords: Organizational improvisation. Management education. Teaching improvisation. Teaching challenges.

\section{Improvisación organizacional: desafíos y perspectivas para la enseñanza-aprendizaje en Administración}

\section{Resumen}

La improvisación organizacional ha sido investigada durante más de 30 años, ya que enfatiza la importancia de sofisticar la práctica de gestores y líderes ante la imprevisibilidad cada vez más marcada en la actualidad. Necesitamos una visión más actualizada de la producción en improvisación organizacional, así como una reflexión sobre cómo integrarla en la formación de los directivos. El objetivo de esta investigación es sistematizar los avances en la producción académica sobre la improvisación organizacional y discutir su integración en la enseñanza-aprendizaje de la Administración. La metodología de investigación consiste en un relevamiento sistemático de la producción académica. Los resultados de la investigación son: (a) un conjunto de puntos relevantes y temas relacionados con la improvisación organizacional, (b) una discusión sobre la importancia de la improvisación organizacional para la investigación en enseñanza-aprendizaje en Administración, (c) un conjunto de enfoques, barreras y perspectivas educativos que ayudan a las investigaciones y prácticas futuras a integrar mejor la improvisación en la enseñanza y el aprendizaje en Administración. El principal aporte de esta investigación es inaugurar una nueva orientación investigadora: la enseñanzaaprendizaje de la improvisación organizacional.

Palabras clave: Improvisación organizacional. Enseñanza-aprendizaje. Enseñanza de la improvisación. Desafíos de la enseñanza. 


\section{INTRODUÇÃO}

A improvisação organizacional (IO) não é um fenômeno novo e foi reconhecida na teoria organizacional (Lewin, 1998) por estar relacionada aos avanços nos estudos sobre liderança, coletividade e redes flexíveis (Hatch, 2002). Essas são a base dos negócios do futuro, o que exige mudanças no perfil do gestor, que hoje se comporta como um técnico moralmente neutro, engajado num mundo de resoluções de problemas racionais e que ignora as emoções. A dificuldade em reconhecer a emoção como parte da prática organizacional esconde a dificuldade de perceber que uma organização é formada por seres humanos com limitações, impulsos, criatividade e emoções (M. P. Cunha, 2002). A emoção é inseparável da IO individual e coletiva, que considera o erro uma parte importante no desenvolvimento de uma ideia, a qual exige negociações, diálogos contínuos e desempenho (Flach \& Antonello, 2011; Weick, 2002). As pesquisas a respeito de 10 ainda não refletem o impacto de sua existência no dia a dia organizacional. A maioria dos artigos publicados é teórico, e os poucos empíricos trabalham com metodologias qualitativas, com ênfase na observação (Barrett, 1998; Flach \& Antonello, 2011; Miner, Bassoff \& Moorman, 2001). Os artigos refletem os aspectos positivos relativos à aprendizagem na prática da IO, porém não falam sobre de que maneira ensiná-la. Não foi encontrada qualquer referência ao ensino-aprendizagem da IO. As poucas revisões da produção acadêmica integram e sistematizam um conteúdo que ainda se mantém disperso e fragmentado, promovendo um entendimento pulverizado sobre o poder da IO (M. P. Cunha, 2014).

A comunidade acadêmica expressa uma preocupação crescente com temáticas relacionadas ao ensino-aprendizagem da administração que carecem de dialogicidade, interdisciplinaridade e integração (Gagliardi \& Czarniawska, 2006). Os problemas apontados vão desde a defasagem na formação de professores até as metodologias ultrapassadas, aliadas à falta de clareza quanto ao significado de competências e habilidades (Nunes, 2010). O debate sobre o poder (Clegg \& Ross-Smith, 2003) e sobre o pouco espaço que os gestores têm para refletir acerca de suas experiências (Mintzberg \& Gosling, 2003) evidenciam as contradições entre teoria e prática na educação gerencial, a qual enfrenta muitos desafios, como a pouca capacidade de levar a qualidade da aprendizagem junto com a expansão do ensino (Oliveira, Loure \& Castro, 2015) e seus sistemas de avaliação (Bolzan \& Antunes, 2015). Embora haja um corpo substancial de pesquisas a respeito da improvisação como fenômeno fundamental nas organizações, há apenas estudos empíricos limitados quanto à aplicação do treinamento de improvisação no local de trabalho (Ratten \& Hodge, 2016). Em toda a produção acadêmica, foram identificados poucos artigos relacionados à aprendizagem da 10 (Barrett, 1998; Falkheimer \& Sandberg, 2018; Flach \& Antonello, 2011; Miner et al., 2001). Mais grave que isso, não há qualquer referência ao ensino-aprendizagem dessa habilidade tão necessária na formação do gestor.

O objetivo deste artigo é discutir e sistematizar os avanços, as perspectivas e os desafios na produção acadêmica sobre a IO e sua integração no ensino-aprendizagem da administração para a formação do gestor contemporâneo. A metodologia de pesquisa consiste numa revisão da produção acadêmica tanto no âmbito da administração quanto no de ciências sociais, humanas e arte. Foi realizado um levantamento extenso das principais bases nacionais e internacionais (Spell, SciELO, Sage Publications, Routledge, Web of Science, Periódicos Capes, Teses Capes, Library of Congress, Emerald, Academy of Management), com foco na produção de 10 e suas relações com questões educacionais. Os termos de busca foram: "IO", "improvisação", "administração", "gestão", "educação", "aprendizagem" e "ensino".

Em paralelo, à medida que a produção acadêmica era identificada, procedíamos à análise das referências citadas para identificar novas referências, como artigos, livros, capítulos de livros, teses, dissertações etc. Tais referências eram pesquisadas, analisadas e integradas ao repertório desta pesquisa. Após uma primeira etapa de seleção, foram verificadas as produções consistentes e coerentes que tratam da IO e suas relações com questões de aprendizagem e ensino. Mapeamos suas referências bibliográficas na busca de outras produções relevantes. Ou seja, o processo de revisão ocorreu dentro de uma lógica de bola de neve, que chegou ao término quando nenhuma referência sobre o tema emergia como nova e relevante. Foram selecionadas e analisadas produções acadêmicas sobre 10 , que incluíam algumas poucas produções a respeito de questões de aprendizagem. A análise da produção acadêmica buscou identificar e categorizar as principais relevâncias, temáticas e carência de pesquisa atual em IO. Uma segunda etapa de análise foi realizada com base na carência de pesquisa identificada, gerando uma categorização voltada para (a) abordagens educacionais em administração, que são afinadas com a IO; (b) barreiras para integrar a IO no ensino-aprendizagem em administração; e (c) perspectivas para integrar a 10 no ensino-aprendizagem da administração.

O artigo está dividido em 3 partes, além desta Introdução. Na primeira, a análise da produção acadêmica em IO é apresentada baseada num conjunto de relevâncias e temáticas. Ainda nessa seção, uma carência de pesquisa é identificada e discutida como desafio para pesquisa futura acerca de ensino-aprendizagem da IO. Na segunda, analisamos, apresentamos e discutimos 
as abordagens educacionais afinadas ao ensino da IO, bem como as barreiras e as perspectivas para integração da 10 no ensino-aprendizagem da IO. Na última, discutimos os resultados da pesquisa em termos de implicações teórico-conceituais, metodológicas e práticas para a pesquisa futura. Esses resultados são discutidos e buscam gerar uma contribuição conceitual para orientar a pesquisa e a prática sobre IO, destacando a importância de renovar e atualizar o ensino-aprendizagem no âmbito da administração.

\section{IMPROVISAÇÃO ORGANIZACIONAL: RELEVÂNCIAS, AVANÇOS E CARÊNCIAS}

As produções acadêmicas sobre IO foram analisadas e geraram 2 grandes eixos de conhecimento: as relevâncias da IO para a administração e as principais temáticas que orientam as pesquisas. Além disso, apresentaremos também as principais definições e metodologias adotadas pelas pesquisas.

A definição de 10 recai sobre processos complexos que abrangem desde respostas rápidas sem preparação prévia até coreografias organizacionais cuidadosamente projetadas com foco nas mudanças organizacionais em ambientes altamente competitivos (M. P. Cunha, 2005). Improvisação é a fusão deliberada de design e execução numa nova produção que envolve a interpretação cognitiva, racional e intuitiva de regras prescritas e padrões de conduta em vários níveis (Giustiniano, M. P. Cunha \& Clegg, 2016). Ela está diretamente ligada às 3 áreas da atividade organizacional: interna (estrutura), externa (turbulência ambiental), e à articulação entre o interno e o externo (M. P. Cunha, Kamoche \& M. P. Cunha, 2003). A improvisação envolve a reelaboração de ideias imprevistas que surgem e são concebidas no decorrer de uma situação em que a adaptação e o desvio são realizados. É preciso um projeto organizacional aberto, que leve em consideração a capacidade criativa dos gestores e seu poder de improvisação, pois aceitar a condição humana de transformação constante é um componente inerente ao trabalho (J. V. Cunha \& M. P. Cunha, 2008).

A IO é definida como a concepção da ação na medida em que se desenvolve com base nos recursos cognitivos, afetivos, sociais e materiais disponíveis (Kamoche, J. V. Cunha \& M. P. Cunha, 2003). Ela acontece quando o planejamento e a execução de uma ação convergem no tempo (Moorman \& Miner, 1998); tem períodos curtos de estabilidade e alto nível de incerteza, dinamismo, complexidade sistêmica, heterogeneidade e velocidade de inovação (J. V. Cunha \& M. P. Cunha, 2000). A IO também acontece em oposição a uma rotina sistemática e que já não funciona como deveria (Weick, 2002), exigindo respostas imediatas (Flach, 2010; Flach \& Antonello, 2011) e permitindo superações (Moorman \& Miner, 1998) dentro de uma estética da imperfeição (Weick, 2002). A 10 como tema na área de organizações e de gestão surgiu associado à metáfora do jazz (Hatch, 1998). Mas, pelo alargamento da base de trabalho teórico e empírico, foi adquirindo proeminência na produção acadêmica e um progressivo valor instrumental (J. V. Cunha \& M. P. Cunha \& Kamoche, 2014). A prática da improvisação funciona como um treinamento para imaginação, criatividade, coletividade, liderança e aprendizagem (Koppett, 2013).

Há vários ensaios teóricos sobre a $\mathrm{IO}$, porém poucos abordam o tema da aprendizagem organizacional por meio da improvisação pelas metáforas (Barrett, 1998; M. P. Cunha, 2002; Flach \& Antonello, 2011). Os 3 estudos empíricos que abordam o tema da aprendizagem relacionada à 10 utilizaram abordagem qualitativa. O primeiro é baseado em multicasos, com entrevistas semiestruturadas, observação direta e análise documental (Flach, 2010). O segundo é indutivo e baseado na observação (Miner et al., 2001). O terceiro consiste em 25 entrevistas qualitativas com uma seleção estratégica de profissionais de comunicação de sucesso, identificados como improvisadores estratégicos típicos (Falkheimer \& Sandberg, 2018).

\section{Relevâncias da Improvisação Organizacional na Área de Administração}

Na pesquisa sobre IO, podemos identificar 8 razões que explicam por que a improvisação é altamente relevante para a área e a prática da administração. A primeira relevância é que a IO permite uma condução positiva na gestão de mudanças em contextos turbulentos. A gestão de mudança é uma articulação entre a estrutura organizacional e as turbulências do ambiente externo (M. P. Cunha, 2002). A IO é vista como uma habilidade útil para essa gestão no contexto de negócios dinâmicos ou turbulentos (Leybourne \& Sadler-Smith, 2006). A IO acontece na prática do dia a dia na administração de problemas que se impõem, gerando uma pressão interna que precisa ser administrada. Quando uma IO acontece, envolve todos e mantém-se viva na memória organizacional por estar associada à diminuição do nível de turbulência (Moorman \& Miner, 1998). Aceitar a turbulência é aceitar a improvisação, é rejeitar o comportamento habitual com um resultado previsível em favor da experimentação e do progresso (Barrett, 2012). Em ambientes marcados por uma constante incerteza, 
que envolvem dinamismo, hostilidade, descobertas, competitividade e mudanças, as empresas são obrigadas a reconhecer a IO como uma habilidade útil para a gestão de mudanças (M. P. Cunha, 2002), que ajuda a entender e questionar a organização como um fluxo contínuo de pessoas que se comunicam e se organizam mutuamente (Weick, 1989), fornecendo insights sobre melhorias para a gestão de mudanças (Crossan, 1998).

A segunda relevância é que ela permite formular e implementar estratégias em cenários cambiantes. É uma característica da improvisação a constante elaboração de estratégias para identificar caminhos que sustentem a resolução de conflitos (Bernstein \& Barrett, 2011), levando em consideração os limites (Moorman \& Miner, 1998). Na IO, a informação é rapidamente compartilhada, servindo como estratégia básica para coordenar ideias complexas que acontecem simultaneamente (Bastien \& Hostager, 1988), aproximando as pessoas dos seus ofícios e ampliando sua capacidade de articulação na busca por soluções (J. V. Cunha \& M. P. Cunha, 2008). A prática da IO é uma estratégia para o desenvolvimento de habilidades (Crossan, 1998) e levanta temas importantes para a criação de políticas organizacionais futuras (Nicholls, 2012) baseadas em práticas (Crossan, 1996).

A terceira relevância é permitir repensar a estrutura organizacional. A IO amplia o conceito de estrutura organizacional (Crossan, 2005; Hatch, 1999, 2002) e desenvolve a noção de estrutura mínima, o que combina aspectos organizacionais, culturais e tecnológicos com sistemas de informação e controle. A gestão dentro da estrutura mínima é capaz de focar a atenção nos aspectos importantes do trabalho, permitindo aos membros da organização fazer aquilo que não estava previsto, em vez de somente o que é explicitamente permitido (M. P. Cunha, 2002) e deliberado. O equilíbrio entre estrutura e improvisação é a forma apropriada de gerenciamento em ambientes muito competitivos (Kamoche \& M. P. Cunha, 2001). É preciso entender melhor a ação dos administradores, em contextos nos quais estruturas e processos formais mais burocratizados "competem" com a dinâmica dos acontecimentos e com a fluência dos processos reconstrutivos nas organizações (Cavalcanti, 2004).

A quarta relevância é habilitar o administrador a tomar decisões sob pressão temporal. Mesmo não existindo total controle sobre um planejamento, decisões precisam ser tomadas (M. P. Cunha, 2014), e elas acontecem de forma planejada ou improvisada. A improvisação revela que nem sempre é possível ter o tempo desejado para ponderações antes de tomar decisões importantes (Hatch, 1998). Improvisar exige um alto grau de concentração, o que mobiliza o corpo e a mente no instante da tomada de decisão. Tomar decisões amplia o repertório de soluções e a capacidade de aprendizagem diante das circunstâncias desenvolvendo aprendizagem sobre o meio e sobre si próprio (Weick, 2002).

A quinta relevância é promover a criatividade no ambiente de trabalho, a qual é uma característica humana que vai sendo desenvolvida e praticada ao longo da vida. No entanto, ela tende a ser reprimida no ambiente organizacional. É preciso transformar a ideia de que a criatividade surge apenas do talento e de expressões individuais, pois pode ser aprendida e praticada (Hallam \& Ingold, 2007). A busca por soluções objetivas em curto espaço de tempo é o que fornece ao corpo o impulso para geração de ideias. Esse impulso é a criatividade (Fisher \& Amabile, 2009; Hallam \& Ingold, 2007; Weick, 2002), que funciona como estímulo para a transformação organizacional (Barber, 2007). A IO proporciona uma prática criativa na busca por soluções, causando certa desordem ao ser reorganizada em seguida (M. P. Cunha \& J. V. Cunha, 2000). Se observarmos as características associadas à organização do século XXI, veremos que criatividade é um desses pilares (Hatch, 1998; Leybourne \& Sadler-Smith, 2006; Montuori, 2003).

A sexta relevância está relacionada aos impulsos que ela promove em direção à inovação. A prática criativa é o caminho para a inovação, e o ambiente organizacional é ideal para a prática criativa pela constante busca por soluções. Os impulsos necessários para inovar são: períodos curtos de estabilidade, alto nível de incerteza, dinamismo, complexidade sistêmica e heterogeneidade (J. V. Cunha \& M. P. Cunha, 2000; Chelariu, Johnston \& Young, 2002). Ao improvisar, o gestor experimenta esses mesmos impulsos na prática. Assim, é conduzido a buscar soluções, algumas delas inovadoras. As empresas bem-sucedidas se diferenciam das organizações menos eficazes por sua capacidade de improvisar e explorar as oportunidades, inovando (Barrett, 2000; Bastien \& Hostager, 1988; Kamoche \& M. P. Cunha, 2001; Kirchbaum, Sakamoto \& Vasconcelos, 2014; Koppett, 2013) e se renovando (Crossan, 1996, 1998; Kamoche et al., 2003).

A sétima relevância está relacionada a aprender a empreender. A habilidade de lidar com um mundo incerto requer de todos os empreendedores um grau de habilidade de improvisação. Os empreendedores iniciam com uma ideia ou um direcionamento, mas muitos obstáculos - recursos limitados, condições inesperadas de mercado ou conflitos com membros da equipe - podem impedi-los de executar seus planos iniciais. Ou seja, eles precisam encontrar um caminho para se adaptar às circunstâncias, pensar em seus desejos e criar novos planos para realizar sua visão. Os empreendedores que detêm competências de IO demonstram melhor desempenho (H. Neck, C. Neck \& Murray, 2018). Na relação entre improvisação, intuição e intenções 
empreendedoras (Leybourne \& Sadler-Smith, 2006), emergem associações com personalidade, motivação, cognição e modelos sociais (Hmieleski \& Corbett, 2006), bem como uma relação positiva com o desempenho de novos empreendimentos (Hmieleski \& Corbett, 2008).

A oitava relevância está em sua capacidade de regenerar a prática da liderança. Com a improvisação, foi possível criar um modelo experimental de liderança num contexto de IO (J. V. Cunha et al., 2003), em que os eventos são os geradores de ação (M. P. Cunha, 2014). Improvisar é um exercício de liderança que aponta para novos caminhos (Flach, 2012), trabalhando uma nova conscientização e uma nova capacidade de liderança coletiva (Scharmer, 2010). Práticas de improvisação teatral para gestores vêm conseguindo ampliar a aprendizagem sobre liderança por meio da criatividade e do trabalho em equipe (Crossan, 1998; Koppett, 2013).

\section{Temáticas da Pesquisa sobre Improvisação Organizacional}

Na pesquisa sobre IO, algumas temáticas se expressam de forma mais recorrente, como a estrutura organizacional, a criatividade, a inovação, a liderança e a aprendizagem organizacional. Outras aparecem de forma menos preponderante, como o tempo, a mudança organizacional, a tecnologia, o marketing, o empreendedorismo, a gestão de projetos, o conflito e a resistência. Nas pesquisas, as temáticas são abordadas de forma isolada ou combinada.

\section{Estrutura organizacional}

Quando surge, a IO parece estar imersa numa ausência de estrutura, mas na realidade está mergulhada num processo criativo moldado por elementos estruturais (M. P. Cunha, 2002). É o momento em que as consequências das ações se desenrolam e vão sendo analisadas e compreendidas simultaneamente pelos atores envolvidos, como gestores, membros da organização, acionistas, clientes ou qualquer outra parte interessada. Isso pode mudar a estrutura de funcionamento pela experiência (Barrett, 1998). A IO permite repensar a estrutura organizacional com base em dimensões emocionais, temporais e relacionais (Hatch, 1999), evidenciando um conjunto de elementos técnicos e sociais que facilitam a ação inovadora, em vez de constrangê-la (Kamoche \& (M. P. Cunha, 2001). As estruturas mínimas não pressupõem uma negociação, pois se complementam sem a necessidade de articulação constante (Barrett, 1998). A improvisação oferece uma combinação única entre estrutura mínima e liberdade que pode revelar novos entendimentos sobre a essência da estrutura organizacional (Hatch, 1999; Kamoche \& (M. P. Cunha, 2001). Tal qual o músico de jazz, o gestor precisa encontrar novas respostas em sua área de atividade, dialogando com a estrutura e, muitas vezes, sem o benefício de certezas quanto aos caminhos e à qualidade das soluções encontradas (Barrett, 1998).

\section{Tempo e mudança organizacional}

As organizações trabalham baseadas num entendimento simplista do tempo: o do relógio (perspectiva linear) e o do evento (perspectiva cíclica). A perspectiva linear está relacionada à passagem do tempo e ao amadurecimento de ideias e procedimentos. A cíclica, por sua vez, trata do tempo que a organização gostaria de ter e que vai dar origem às metas, aos planejamentos e aos procedimentos. Com o conceito de improvisação, é possível aproximar essas 2 perspectivas superando a ideia de que uma se contrapõe à outra (Crossan \& Sorrentti, 1997). Na prática, a IO oferece o suporte analítico-conceitual para compreender a dinâmica e a subjetividade da relação entre as 2 perspectivas temporais no cotidiano organizacional, uma vez que consegue estabelecer elementos de análise e identificar aspectos contraditórios entre elas (Aranha \& Garcia, 2005). Na improvisação, não temos o tempo desejado para encontrar a solução e amadurecemos junto com a questão apresentada.

\section{Tecnologia e marketing}

As intervenções de marketing improvisadas (IMIs) são ações de mídia social, compostas e executadas em tempo real, próximas a um evento externo. O foco recai no conceito de raciocínio rápido, promovendo humor, pontualidade ou imprevisibilidade. É por meio dos IMIs que podemos perceber evidências sobre o valor da organização. Essas descobertas apontam para o potencial dos IMIs nas mídias sociais e para os recursos que as organizações devem investir a fim de colher os benefícios observados do compartilhamento on-line (Borah et al., 2020). 


\section{Criatividade e inovação}

Toda inovação se origina de uma prática criativa, mas nem toda prática criativa leva à inovação. A criatividade é tema recorrente em todas as produções acadêmicas que versam sobre a IO, pois é uma característica inerente à improvisação. Porém, deve ser compreendida como uma propriedade emergente da relação entre ordem e desordem, envolvendo aspectos mais sociais do que individuais (Montuori, 2003). A capacidade e a disponibilidade do gestor de abrir mão do que foi planejado por uma solução criativa criada ao sabor do momento enfatiza a colaboração e pode trazer a inovação aos que saibam cooperar (M. P. Cunha, 2002).

\section{Empreendedorismo}

Os empreendedores enfrentam constantemente situações inesperadas e inusitadas. Aqueles que prosperam são improvisadores. Com base nos princípios desenvolvidos na prática da improvisação é possível promover a mentalidade empreendedora. Pela improvisação, os empreendedores podem aprender a prestar atenção às condições interpessoais do presente e do futuro, a fim de adaptar potenciais limitações para o sucesso do empreendimento (Balachandra, 2019; H. Neck et al., 2018).

\section{Liderança}

Os líderes podem adotar uma mentalidade que maximiza o aprendizado, permanecem responsivos às oportunidades emergentes de curto prazo e, ao mesmo tempo, fortalecem capacidades dinâmicas da organização (Bernstain \& Barrett, 2011). A liderança deve pensar o grupo como criativo, dentro de um sistema bem-distribuído, com controle descentralizado, em que muitas vezes será preciso apostar em ideias que não tenham respaldo em pesquisas, mas que acompanham raciocínio e tentativas do grupo (Barrett, 2012).

\section{Gestão de projetos}

A improvisação é um atributo organizacional que promove o exercício da prática e da adaptação na gestão (Hatch, 1998; Lewin, 1998). A prática da improvisação envolve a de gestão (Crossan, 1998), entendida como uma aprendizagem social, coletiva e criativa (Sawyer, 2000). A adaptação organizacional acontece à medida que se improvisa, se inova e se ajusta a rotina de trabalho ao longo do tempo (Orlikowski, 1996). A IO ajuda a explicar novas maneiras de se organizar na prática da gestão (Orlikowski, 2000) de forma emergente e oportuna (Orlikowski \& Hofman, 1997), ampliando a escuta (Caines \& Heble, 2015), exercitando a resiliência (Weick, 1993) e podendo alcançar a originalidade (Leybourne, 2009). As organizações contemporâneas se situam num mundo complexo e em transformação, em que a IO pode se transformar num instrumento precioso para a gestão de projetos (M. P. Cunha, 2002).

\section{Conflito e resistência}

A relação entre competição e cooperação dentro do ambiente organizacional pode ser uma combinação geradora de conflitos. Na IO, competição e cooperação são geradores de criatividade na resolução de conflitos, melhorando a capacidade de administração deles (Kirchbaum et al., 2014). Mais do que pessoas com um repertório de soluções variadas que saibam competir, algumas situações exigem, sobretudo, pessoas com capacidade de aprendizagem rápida para cooperar, ou seja, capazes de escolher uma solução ajustada às circunstâncias, quebrando resistências (Weick, 1993). O processo de resistir a algo, como na guerra, pressupõe um quadro de mudança contínua, pois não se sabe ao certo quais serão os passos do inimigo. A construção da resistência é um ato de improvisação, pois é o momento em que regras e estruturas podem ser temporariamente suspensas.

\section{Aprendizagem organizacional}

Pesquisas sobre $\mathrm{IO}$ e aprendizagem organizacional fornecem uma lente acerca da aprendizagem do empreendedorismo, a inovação tecnológica e a fusão de mudanças e ordens não planejadas (Miner et al., 2001). O processo da IO tem implicações comprovadas na aprendizagem organizacional, pois desponta para lidar com problemas não premeditados e que exigem resolução imediata. Assim, proporciona uma articulação direta com o processo prévio e posterior de aprendizagem na tentativa, no acerto e no erro (Flach, 2010; Miner et al., 2001). Os líderes podem adotar uma mentalidade que maximiza o aprendizado, aproveitando as oportunidades de curto prazo que surgem e, ao mesmo tempo, fortalecendo as capacidades dinâmicas da organização (Bernatein \& Barrett, 2011). 


\section{Desafio para a Pesquisa Futura: Ensino-aprendizagem da Improvisação Organizacional}

\section{A aprendizagem para improvisar}

A improvisação apresenta um tipo distinto de aprendizado em tempo real, tanto de curto quanto de longo prazo (Miner et al., 2001). É possível observar a IO, concentrando-se no papel do fluxo de informações e na interação ação-aprendizado, conforme a organização responde a um ambiente de mudanças ou uma crise (Chelariu et al., 2002). A aprendizagem pode ocorrer antes - conhecimento de estruturas mínimas, normas, regras e experiências anteriores -, durante - o tempo real no qual são criados novos caminhos, formas e estruturas, em que existe a procura pela solução do problema dentro de um período curto, promovendo experiências, ações e mudanças que convergem no tempo - e após o improviso - com a permanência na memória e na possibilidade de reflexão sobre erros e acertos na busca por outras soluções possíveis (Flach, 2010).

\section{O ensino para aprender a improvisar}

O ensino-aprendizagem da IO aparece como uma carência na produção acadêmica. A habilidade de improvisação pode ser ensinada para os membros de uma organização por meio de treinamento teatral, criando mudanças comportamentais no indivíduo e na organização (Vera \& Crossan, 2005). Todavia, nada foi encontrado sobre ensino-aprendizagem da IO. Essa carência evidencia também a ausência de prática nas instituições de ensino, uma vez que a 10 é um recurso implícito para aqueles que estão praticando uma ação pela primeira vez. Os ajustes entre o corpo e a mente no instante da aprendizagem constitui a essência da IO.

\section{ENSINO-APRENDIZAGEM DA IMPROVISAÇÃO ORGANIZACIONAL: ABORDAGENS, DESAFIOS E PERSPECTIVAS}

\section{Abordagens Educacionais em Administração Afinadas com a IO}

O processo de ensino-aprendizagem e a interação entre professores e estudantes no ensino superior envolve planejamento e interação do aprendizado, dentro e fora da sala de aula, e a avaliação do desempenho como parte da construção da aprendizagem (Beni et al., 2017). O posicionamento das universidades, as vertentes da administração, o perfil do estudante e a relação entre currículo e ação docente compõem a dimensão estrutural e institucional do ambiente de aprendizagem da administração (Lima \& Silva, 2017). Mesmo diante da importância da prática na formação profissional em administração, há fragilidade nos estudos sobre questões voltadas para a prática (Cassundé, 2017).

A educação profissional é paradoxal e apresenta descontentamento por parte dos estudantes e dos professores (Argyris \& Schon, 1974). Estudiosos criticam a ênfase excessivamente analítica no ensino, que causa o sufocamento da criatividade e pouca integração entre ensino e pesquisa, acarretando desconexão entre teoria e prática, entre saber e fazer (Wankel \& DeFillippi, 2006). O campo da administração tem sido marcado por um conflito no qual o gestor é visto como um técnico cuja prática consiste em aplicar aos problemas cotidianos de sua organização princípios e métodos derivados da ciência da administração (Schon, 1983). O ensino superior, em muitas partes do mundo, ignorou que práticas podem contribuir para nossa base de conhecimento de maneira interativa e distinta da educação em sala de aula. Ou seja, é possível fazer uma síntese entre a teoria e a prática, utilizando conhecimento tácito, reflexão crítica e maestria (Raelin, 2007).

As pesquisas apontam para uma necessidade de reestruturação de paradigmas numa constante avaliação da prática educacional em administração e do próprio desenvolvimento da gestão, gerando reflexão sobre a prática organizacional (Czarniawska \& Gagliardi, 2003). É urgente a necessidade de incorporação de uma prática dialógica reflexiva com o objetivo de desenvolver profissionais mais críticos, responsáveis e conectados ao conhecimento tácito e explícito (Cunliffe \& Easterby-Smith, 2004). As metodologias ativas buscam auxiliar a conquista de níveis complexos de pensamento e de comprometimento por terem princípios baseados na promoção da autonomia, na descoberta de potencialidades e na melhoria da qualidade do ensino-aprendizagem. $O$ desenvolvimento da autonomia é parte fundamental nesse processo por se tratar da capacidade de governar a si mesmo dentro de uma liberdade ou independência moral e intelectual (Berbel, 2011).

Vivemos um período de defesa da interdisciplinaridade (Paiva, Esther \& Melo, 2004), em que a atitude é parte do desenvolvimento das ações (Bresler, 2002) na busca desse tornar uma experiência transformadora (Dewey, 1938). Se a educação é uma prática da liberdade (Freire, 2005), a ausência de prática (H. Neck et al., 2018; Steyaert, Beyes \& Parker, 2016) caracteriza o perigo de educar gestores de acordo com princípios lineares quase inexistentes num mundo complexo e com processos não lineares (Aram \& Walochik, 1997). 
Entre as abordagens educacionais em administração, destacamos e apresentamos 4 que se afinam com os princípios da IO (Quadro 1): experiencial, humanística, artística e empreendedora.

Quadro 1

Conexões das abordagens educacionais com a improvisação organizacional

\begin{tabular}{|c|c|c|c|}
\hline $\begin{array}{l}\text { Abordagens } \\
\text { educacionais }\end{array}$ & Descrição & Conexão com a 10 & $\begin{array}{l}\text { Principais } \\
\text { Referências }\end{array}$ \\
\hline Experiencial & $\begin{array}{l}\text { O princípio de toda ação pedagógica é proporcionar ao } \\
\text { estudante a curiosidade em que as ações manuais e intelectuais } \\
\text { promovem uma contínua construção e reconstrução de } \\
\text { experiências. Nessa abordagem, o conceito de aprendizagem } \\
\text { representa uma estrutura para entender os estilos de } \\
\text { aprendizagem dos estudantes e o ambiente institucional de } \\
\text { aprendizagem. O aprendizado experiencial multidisciplinar } \\
\text { baseado em equipe e em prática é comum em situações de } \\
\text { desenvolvimento profissional. A prática coloca o mental em } \\
\text { conexão com o corpo e com as ferramentas nos trabalhos aos } \\
\text { quais se aplica. O aprendizado experiencial de gestão enfrenta } \\
\text { resistências tanto de acadêmicos quanto de gerentes, mesmo } \\
\text { sendo uma alternativa para aprender valores sociais e políticos } \\
\text { no contexto educacional e organizacional. }\end{array}$ & $\begin{array}{l}\text { Corpo como parte no } \\
\text { desenvolvimento das ações. } \\
\text { Prática como uma experiência } \\
\text { transformadora. } \\
\text { Maior aproximação com as } \\
\text { ferramentas de trabalho. }\end{array}$ & $\begin{array}{l}\text { Bruner (1996); } \\
\text { Kolb (1984); } \\
\text { Kolb e Kolb (2005); } \\
\text { Reynolds (2009); } \\
\text { Vergara (2003). }\end{array}$ \\
\hline Humanística & $\begin{array}{l}\text { A abordagem humanística na educação gerencial contribui } \\
\text { para mudar a instrumental para uma abordagem mais } \\
\text { transformadora do ensino e da aprendizagem. O debate } \\
\text { sobre o futuro da educação em administração, sobretudo } \\
\text { no que diz respeito à integração de humanidades e ciências } \\
\text { sociais, tem grande influência na aceitação geral das escolas } \\
\text { de administração e na melhoria da educação gerencial. A } \\
\text { pedagogia, a abordagem e a razão críticas aparecem nisso } \\
\text { tudo como um caminho para possíveis mudanças, podendo } \\
\text { trazer mais humanismo para as elites gerenciais. }\end{array}$ & $\begin{array}{l}\text { Abordagem transformadora. } \\
\text { Abordagem crítica. }\end{array}$ & $\begin{array}{l}\text { Faria, Meneghetti } \\
\text { e Stefani (2016); } \\
\text { Landfaster e } \\
\text { Metemann (2019); } \\
\text { Maranhão e } \\
\text { Paula (2011); } \\
\text { Paula e Rodrigues } \\
\text { (2006); } \\
\text { Steyaert et al. (2016). }\end{array}$ \\
\hline Artística & $\begin{array}{l}\text { Na última década, inúmeras escolas de administração } \\
\text { começaram a experimentar arte para solucionar problemas } \\
\text { e inovar com o objetivo de educar gerentes por meio da prática. } \\
\text { As artes potencializam as mudanças educacionais com uma } \\
\text { peça teatral, para o ensino-aprendizagem de competências; } \\
\text { com literatura, para abordar assuntos complexos e delicados; } \\
\text { com uma experiência estética, como filmes, para o debate } \\
\text { sobre comportamento organizacional e aprendizagem social; } \\
\text { ou como caminho para a criatividade, por desenvolver a } \\
\text { capacidade de conhecer e sentir. As artes são uma fonte } \\
\text { inesgotável de recursos pedagógicos e de inspirações com } \\
\text { sua energia transformadora aplicada aos estudos sobre } \\
\text { ensino-aprendizagem da administração que tem um ambiente } \\
\text { multidimensional, de alta complexidade, alimentado por } \\
\text { questões objetivas e subjetivas. As práticas artísticas auxiliam } \\
\text { na aprendizagem e na experimentação das dimensões que } \\
\text { giram em torno de conflitos, tensões emocionais e incertezas. }\end{array}$ & $\begin{array}{l}\text { Inovação. } \\
\text { Estímulo à criatividade. } \\
\text { Potencializa mudanças } \\
\text { Aborda assuntos complexos } \\
\text { com naturalidade. } \\
\text { Desenvolvimento da } \\
\text { capacidade de conhecer e } \\
\text { sentir. } \\
\text { Diálogo entre questões } \\
\text { objetivas e subjetivas. }\end{array}$ & $\begin{array}{l}\text { Amaral e Leite (2016); } \\
\text { Barry e Meisiek } \\
\text { (2015); Bureau } \\
\text { e Komporozos- } \\
\text { Athanasion (2017); } \\
\text { Davel, Vergara e } \\
\text { Ghadiri (2007); } \\
\text { Dewey (1938); } \\
\text { Fisher e Amabile } \\
\text { (2009); } \\
\text { Irgens (2014); } \\
\text { Mack (2012); } \\
\text { Oliveira et al. (2015). }\end{array}$ \\
\hline Empreendedora & $\begin{array}{l}\text { A aprendizagem da improvisação oferece um viés promissor } \\
\text { para investigar processos empreendedores, pois muitos deles } \\
\text { não formulam planos cuidadosos ao iniciar seus negócios, } \\
\text { mas respondem bem a oportunidades repentinas, tal qual a } \\
\text { definição de improvisação. A estrutura da improvisação pode } \\
\text { iluminar as organizações empreendedoras ao utilizar de forma } \\
\text { criativa materiais disponíveis ou trazendo positividade para } \\
\text { os impactos causados pela transição e pela implementação } \\
\text { de novos conceitos e procedimentos. }\end{array}$ & $\begin{array}{l}\text { Imprevisibilidade. } \\
\text { Inovação. } \\
\text { Novas utilizações de diferentes } \\
\text { tipos de materiais. } \\
\text { Fortalecimento da positividade. } \\
\text { Adaptação a novos conceitos e } \\
\text { procedimentos. }\end{array}$ & Miner et al. (2001). \\
\hline
\end{tabular}

Fonte: Dados da pesquisa. 


\title{
Barreiras para Integrar a IO no Ensino-Aprendizagem em Administração
}

\author{
Institucionalização do ensino-aprendizagem como prática de reflexão essencialmente mental, com atividades práticas \\ superficiais
}

Existe uma prática constante por parte do corpo docente de cursos de administração em ministrar aulas expositivas que não desenvolvem possibilidades de envolvimento do estudante num ambiente plural. A prática de uma reflexão, essencialmente mental, com atividades práticas superficiais não proporciona experiências e caracteriza referências apenas teóricas. A separação entre teoria e prática constitui uma razão para a falta de sequência lógica de conteúdo com excesso de aulas expositivas e pouco exercício de autonomia e de tomada de decisões (Cezarino \& Corrêa, 2015). Para conseguir manter o corpo em real conexão com a mente, é preciso ações, objetivos e paradigmas de complexidade. 0 debate envolve desde a história da administração e o estudo de vida de seus mestres e instituições até o legado do ensino e dos programas desenvolvidos, incluindo os currículos (Fisher, Waiandt \& Fonseca, 2011). Uma constante revisão histórica acerca dos desafios e das tendências do ensino-aprendizagem da administração (Oliveira et al., 2015) indica que, quando a aprendizagem ocorre num ambiente no qual a pluralidade discursiva é aceita e reconhecida e no qual as diferenças são toleradas, o aproveitamento é maior (Clegg \& Ross-Smith, 2006).

\section{Intimidação do educador em relação à linguagem artística aplicada no ensino-aprendizagem}

Um desafio delicado nas relações de ensino-aprendizagem da administração é a ausência de paradigmas de complexidade e excesso de linhas de pesquisa estritamente positivista. Um estudo mais apurado nos processos de aprendizagem da administração aponta para a importância da sutileza e dos aspectos emocionais que encontramos nas artes. A adoção de metodologias artísticas traz à tona os aspectos relacionados à complexidade e à dimensão emocional necessárias à compreensão da ação dinâmica que a gestão requer. No entanto, a docência ainda subestima o poder da arte ou se sente intimidada ao utilizá-la em função das inúmeras portas que abre. As metodologias artísticas, quando utilizadas, apresentam um diferencial na aprendizagem e um aproveitamento de abordagens relativas ao campo do ensino-aprendizagem da gestão. Essa intimidação pode estar atrelada ao pouco conhecimento das metodologias artísticas, mas também à descrença na eficácia delas, mesmo com tantos casos comprovados e escritos. A arte ajuda a melhor posicionar os estudantes, estimulando a criação de vínculos entre eles e favorecendo uma relação de convívio com o professor. Esse docente se desloca de uma posição de simples transmissor para o de coprodutor do conhecimento, ancorando a aprendizagem na experiência, na reciprocidade e na interatividade (Davel et al., 2007).

\section{Perspectivas para Integrar a IO no Ensino-Aprendizagem em Administração}

A observação da improvisação nas artes para a construção teórica da IO, seja com o jazz (Barrett, 1998; M. P. Cunha, 2002; Hatch, 1998, 1999; Zack, 2000), seja com o teatro (Crossan, 1998; Koppett, 2013; Vera \& Crossan, 2004, 2005), tem sido discutida na literatura internacional e lança luzes para discutir como o fenômeno da improvisação pode contribuir para novas interpretações da aprendizagem organizacional (Barrett, 1998; Flach \& Antonello, 2011; Miner et al., 2001). Podemos pensar 2 perspectivas para integrar a 10 no ensino-aprendizagem da administração: a musical e a teatral.

Na perspectiva musical, o jazz tem em sua estrutura uma combinação entre a improvisação e um conjunto de regras altamente precisas (Barrett, 1998; Hatch, 1999; Zack, 2000) em que os músicos vivem um ambiente instável, interpretando pistas vagas, processando informações, formulando e implementando estratégias simultaneamente, inventando respostas sem planos bem pensados e sem garantia de resultados (Barrett, 2000; Weick, 1998). Trata-se de um trabalho coletivo e integrado (Bastien \& Hostager, 1988), que traz implicações para o campo da administração e amplia os debates em assuntos que vão desde o design organizacional (Barrett, 1998) até as inovações em estratégias de marketing (Moorman \& Miner, 1998). O profissional que tem conhecimento em 10 pode transformar um problema em solução (Caines \& Heble, 2015), experimentando uma liderança lógica também conhecida como mentalidade do jazz (Bernstein \& Barrett, 2011) e descobrindo o futuro que sua ação cria ao mesmo tempo que ela se desenrola (Barrett, 2000).

Na prática, o professor não precisa ser um músico de jazz nem tocar algum instrumento para propor uma dinâmica que mobilize a música na improvisação. É possível desdobrar a experimentação musical e dar ênfase a diferentes características, como o ritmo. Para improvisar, é preciso estar plenamente conectado aos que estão à sua volta. Os exercícios de ritmo são bons para 
que todos se percebam dentro de um mesmo tempo. Outra possibilidade de mobilização da música é a coordenação motora com pequenas coreografias (gestos livres) que são criadas no momento da aula e com a participação de todos. Quando a turma já estiver mais entrosada, a criação musical pode se tornar uma atividade frutífera para que os aprendizes expressem tudo o que aconteceu em seu dia até o momento da aula.

Na perspectiva teatral, é possível fazer uma ponte entre a teoria e a prática improvisacional na gestão por meio da improvisação teatral (Crossan, 1998). A improvisação teatral para a gestão aparece como modelo teórico e tem um efeito positivo na inovação, ressaltando os princípios da prática, da colaboração, da aceitação e da presença (Vera \& Crossan, 2005). A metáfora do teatro reconhece a natureza equívoca e imprevisível da improvisação, enfatizando sua contribuição para o processo, e não tanto para o resultado (Vera \& Crossan, 2004), a exemplo da Commedia Dell'arte, gênero de teatro improvisado, surgido na Europa no século XVI (Crossan \& Sorrenti, 1997). Com o teatro, é possível vivenciar o risco, a liderança e a ambiguidade que envolvem o tempo presente e as informações do tempo passado na tomada de decisão (March \& Weil, 2005). Faz tempo que as artes vêm ajudando o campo do ensino-aprendizagem da administração, mas ainda encontra resistência em ser assumida como dimensão fundamental para a construção do conhecimento.

O uso do teatro em sala de aula ajuda na compreensão corporal de como devemos estar preparados para a gestão. Não é necessário ser uma pessoa de teatro para pedir ao estudante que relate uma situação em forma de cena. Ao reproduzir em cena uma situação real que aconteceu com o estudante, muitos detalhes e reflexões vêm à tona. Em vez de a pessoa dizer que teve de resolver um conflito de equipe, ela precisa fazer a cena de como isso aconteceu, do início ao fim. $O$ tempo que se tem em sala de aula para uma dinâmica como essa é suficiente para sua realização, pois o tempo de combinação entre os grupos para explicar a situação a ser encenada, a distribuição de papéis e as definições espaciais não pode ser longo, a fim de desenvolver prontidão e raciocínio rápido. Depois de apresentada a cena, o debate se encarrega de trazer à baila outros detalhes e outras situações relacionadas ao tema proposto.

\section{DISCUSSÃO E CONCLUSÃO}

Os resultados da pesquisa proporcionam um entendimento da produção acadêmica sobre IO baseado em suas várias relevâncias, temáticas e carências. Uma carência que se demarca é voltada ao ensino-aprendizagem da IO. Então, como resultados, também mapeamos 4 abordagens nas pesquisas sobre ensino-aprendizagem em administração que apresentam conexão com as pesquisas sobre IO, bem como barreiras e perspectivas de integração da IO na atividade educacional. Entre abordagens e perspectivas, as artes representam um elo fundamental para a melhoria do ensino da gestão e das perspectivas de futuro. Este estudo vem selar a união destes 2 campos do conhecimento - arte e administração -, apontando direções frutíferas para a pesquisa e a prática do ensino-aprendizado da IO.

Algumas implicações emergem dos resultados da pesquisa. A primeira delas é a teórico-conceitual. Os resultados dessa pesquisa estimulam novos estudos em 10 para enfocar, teórica e empiricamente, o ensino, já que as pesquisas existentes tratam somente da aprendizagem (Barrett, 1998; Falkheimer \& Sandberg, 2018; Flach \& Antonello, 2011; Miner et al., 2001). Assim, pesquisas futuras poderão aprofundar o entendimento sobre como organizações dinâmicas requerem pessoas que desenvolvem suas habilidades de improvisação (Mannucci, Orazi \& Valck, 2020; Tabesh \& Vera, 2020). É necessário repensar, de forma teórica e robusta, a IO como um fenômeno de ensino-aprendizagem, levando em conta que o teatro e a música são campos artísticos fecundos para orientar pesquisas futuras sobre ensino-aprendizagem da 10 em administração. Devem-se associar as teorias de ensino-aprendizagem da gestão com as de ensino-aprendizagem e experimentação da música e do teatro, pois elas fazem a conexão entre as práticas do presente e do futuro. Quando refletimos teoricamente sobre esse conjunto de teorias, é possível encontrar aproximações e lacunas em que o campo das artes auxilia o da gestão, e vice-versa.

A segunda implicação é metodológica. As metodologias baseadas em arte são pouco mobilizadas no campo da administração (Blumenfeld-Jones, 1995; Boje, Rosile, Durant \& Luhnian, 2004; Czarniawska-Joerges, 1995; Grisoni, 2006; Hardy, 1999; Hatch, 2002, 2008; Patien et al., 2003; Silva \& Vergara, 2002; Sorensen, 2014), mas poderiam abrir novas vias de pesquisa empírica, relevante e inovadora sobre o ensino-aprendizagem da IO. Elas ajudam a ir além do que pode ser visto no primeiro plano do entendimento, pois a experiência com a arte é invariavelmente sensível, profunda e captadora de sutilezas (Chilton, 2013; Silva, 2000; Sullivan, 2010; Young, 2001). Assim, essas metodologias permitem desenvolver pesquisas 
empíricas mais sofisticadas no que se refere à educação e à formação de gestores (Gagliardi \& Czarniawska, 2006). Há uma necessidade latente de pesquisas empíricas voltadas para o campo do ensino-aprendizado com foco na prática e na IO. O empírico é estimulante para a criação de novas abordagens e novas reflexões. Isso ocorre porque as pesquisas empíricas sobre 10 são raras e abordam somente aspectos ligados à aprendizagem, trabalhando com metodologias qualitativas, com ênfase na observação e no uso de metáforas (Barrett, 1998; Falkheimer \& Sandberg, 2018; Flach \& Antonello, 2011; Miner et al., 2001). Entendemos a preocupação quanto aos limites de utilizar uma metodologia artística, tanto os da condução quanto os da avaliação, mas esse entendimento pode ser suavizado se levarmos a metodologia para o campo da experimentação.

A terceira implicação é prática. É no âmbito da prática que ativamos a aprendizagem e o ensino da gestão (Aram \& Walochik, 1997; Berbel, 2011; Bresler, 2002; Cunliffe \& Easterby-Smith, 2004; Czarniawska \& Gagliardi, 2003; Dewey, 1938; Freire, 2005; H. Neck et al., 2018; Paiva, Esther \& Melo, 2004). A prática é o caminho para o surgimento e a realização da improvisação, componente fundamental na formação do gestor contemporâneo. Ao adotar o exercício teatral ou musical como ferramenta de ensino, os estudantes poderão desenvolvê-las e aperfeiçoá-las em âmbito profissional e organizacional. A ação artística poderá melhorar a capacidade de reação dos estudantes e ajudar os professores no refinamento de suas experiências pedagógicas. Os educadores dispõem de uma reflexão sobre a importância de incluir a improvisação em suas preocupações de ensino, em que todos ganham. Existe uma diferença importante entre executar algo e pensar em executar algo. A quantidade de ações desencadeadas para executar uma ideia é facilmente percebida numa dinâmica prática. Entretanto, é pouco entendida numa observação teórica se o estudante não tiver vivenciado antes algo parecido. A execução conecta os objetivos às ações e torna evidente se o indivíduo está trabalhando a favor de ou contra si mesmo. 


\section{REFERÊNCIAS}

Aram, J. D., \& Walochik, K. (1997). Improvisation and the Spanish Manager. International Studies of Management \& Organization, 26(4), 73-89.

Aranha, E., \& Garcia, N. (2005). Improvisação organizacional, jazz e as representações do tempo na organização. Revista Ibero-Americana de Estratégia, 4(1), 79-87.

Argyris, C., \& Schon, D. (1974). Theory in Practice: Increasing Professional Effectiveness. San Francisco, CA: Jossey-Bass.

Balachandra, L. (2020). The Improvisational Entrepreneur: Improvisation Training in Entrepreneurship Education. Journal of Small Business Management, 57(1), 60-77.

Barber, K. (2007). Improvisation and the Art of Making things Stick. In E. Hallam, \& T. Ingold (Eds.), Creativity and Cultural Improvisation. New York, NY: Berg.

Barrett, F. J. (1998). Creativity and Improvisation in Jazz and Organizations: Implications for Organizational Learning. Organization Science, 9(5), 605-622.

Barrett, F. J. (2000). Cultivating an aesthetic of unfolding: jazz improvisation as a self-organizing system. In S. Linstead, \& H. Hopfl (Eds.), The Aesthetics of Organization. London, UK: Sage Publications.

Barrett, F. J. (2012). Yes to the Mess: Surprising Leadership Lessons from Jazz. Cambridge, MA: Harvard Business School Press.

Bastien, D. T., \& Hostager, T. J. (1988). Jazz as a Process of Organizational Innovation. Communication Research, 15, 582-602.

Beni, P. F., Breno, F. R., Villela, L. M., Esteve, R., Jones, G. D. C., \& Forte, D. (2017). Processo de ensino-aprendizagem e a interação de professores e alunos em um curso de graduação em Administração de Empresas. Administração - Ensino e Pesquisa, 18(2), 345-374.

Berbel, N. A. N. (2011). As metodologias ativas e a promoção da autonomia de estudantes. Semina - Ciências Sociais e Humanas, 32(1), 25-40.

Bernstein, E. S., \& Barrett, F. J. (2011). Strategic Change and the Jazz Mindset: Exploring Practices that Enhance Dynamic Capabilities for Organizational Improvisation. Research in Organizational Change and Development, 19, 55-90.

Blumenfeld-Jones, D. S. (1995). Dance as mode of research representation. Qualitative Inquiry, 1(4), 391-401.

Boje, D. M., Rosile, G. A., Durant, R. A., \& Luhnian, J. T. (Eds.), (2004). Enron Spectacles: A Critical Dramaturgical Analysis. Los Angeles, CA: Sage Publication.

Bolzan, L. M., \& Antunes, E. D. D. (2015). O que clamam as vozes dos pesquisadores e sobre o que elas se calam ao abordarem o ensino em administração no Brasil? Revista do Mestrado em Administração e Desenvolvimento Empresarial, 19(3), 77-93.

Borah, A., Banerjee, S., Lin Y., Jain, A., \& Eisingerich, A. B. (2020). Improvised Marketing Interventions in Social Media. American Marketing Association, 84(2), 69-91.

Bresler, R. (2002). Novos contornos da gestão local: conceitos em construção. Revista de Administração de Empresas, 43(3), 108-109.
Caines, R., \& Heble, A. (2015). The Improvisation Studies Reader: Spontaneous Acts. London, UK: Routledge.

Cassundé, F. (2017). [Re]pensando o estágio na formação profissional dos estudantes de administração: um estudo sobre a produção científica brasileira na área. Administração - Ensino e Pesquisa, 18(3), 594-623.

Cavalcanti, B. (2004). Da modelagem à improvisação: reinterpretando a modelagem organizacional. Revista de Administração Pública, 38(4), 589-611.

Cezarino, L. O., \& Corrêa, H. L. (2015). Interdisciplinaridade no ensino em administração: visão de especialistas e coordenadores de cursos de graduação. Administração - Ensino e Pesquisa, 16(4), 751-784.

Chelariu, C., Johnston, W. J., \& Young, L. (2002). Learning to Improvise, Improvising to Learn: A Process of Responding to Complex Environments. Journal of Business Research, 55, 141-147.

Chilton, G. (2013) Altered Inquiry: Discovering Arts-Based Research Through an Altered Book. International Journal of Qualitative Methods, 12(1), 457-477.

Clegg, S. R., \& Ross-Smith, A. (2006). Revising the Boundaries: Management Education and Learning in a Postpositivist World. Academy of Management Learning \& Education, 2(1), 85-98.

Crossan, M. (1996). The Improvising Organizations: When Planning Meets Opportunity. Organizational Dynamics - Spring (14), 20-35.

Crossan, M. (1998). Improvisation in Action. Organization Science, 9(5), 593-599.

Crossan, M. C., Cunha, M. P., Vera, D., \& Cunha, J. V. (2005). Time and Organizational Improvisation. Academy of Management Review, 30(1), 129-145.

Crossan, M., \& Sorrenti, M. (1997). Making Sense of Improvisation. Advances in Strategic Management, 14, 155-180.

Cunha, J. V., \& Cunha, M. P. (2008). Improvisation in Organizations. In Barry, D., \& Hansen, H. (Eds.), The Sage Handbook of New Approaches in Management and Organization. Los Angeles, CA: Sage Publications.

Cunha, J. V., Cunha, M. P., \& Kamoche, K. (2003). Organizational Improvisation: a Contextual Approach. International Review of Sociology, 13(3), 567-589.

Cunha, M. P. (2002). All that jazz: três aplicações do conceito de improvisação organizacional. Revista de Administração de Empresas, 42(3), 36-42.

Cunha, M. P. (2005). A arte dos improvisadores: a busca da estandardização na música e nas organizações. Organizações \& Sociedade, 12(32), 93-104.

Cunha, M. P. (2014). Organizational Improvisation: From the Constraint of Strict Tempo to the Power of the Avant-Garde. Creativity and Innovation Management, 23(4), 359-373.

Cunha, M. P., \& Cunha, J. V. (2000). Improvisação e organização. In Rodrigues, S. B., \& Cunha, M. P. (Eds.), Estudos organizacionais: novas perspectivas na administração de empresas - uma coletânea Luso-Brasileira. São Paulo, SP: Editora Iglu. 
Cunha, M. P., Cunha, J. V., \& Kamoche, K. (1999). Organizational improvisation: what, when, how and why. International Journal of Management Reviews, 1, 299-341.

Cunha, M. P., Cunha, R. C., \& Kamoche, K. N. (2014). Organizational Improvisation and Leadership - A Field Study in Two ComputerMediated Settings. International Studies of Management \& Organization, 33(1), 34-57.

Cunha, M. P., Kamoche, K. N., \& Cunha, R. C. (2003). Organizational Improvisation and Leadership-A Field Study in Two Computer-Mediated Settings. International Studies of Management \& Organization, 33(1), 34-57.

Cunliffe, A. L., \& Easterby-Smith, M. (2004). From reflection to practical reflexivity: Experiential learning as lived experience. In M. Reynolds, \& R. Vince (Eds.), Organizing reflection (pp. 30-46). London, UK: Ashgate.

Czarniawska, B., \& Gagliardi, P. (2003). Narratives we organize by. Amsterdam, The Netherlands: John Benjamins Publishing Company

Czarniawska-Joerges, B., \& Jacobsson, B. (1995). Political Organizations and Commedia Dell'Arte. Organization Studies, 16(3), 375-394.

Davel, E., Vergara, S., \& Ghadiri, D. (2007). Administração com arte: experiências vividas de ensino-aprendizagem. São Paulo, SP: Editora Atlas.

Dewey, J. (1938). Experience and ducation. New York, NY: Touchstone Book.

Falkheimer, J., \& Sandberg, K. G. (2018). The Art of Strategic Improvisation: A Professional Concept for Contemporary Communication Managers. Journal of Communication Management, 22(2), 253-258.

Faria, J. H., Meneghetti, F. K., \& Stefani, D. (2016). Razão tradicional e razão crítica: os percursos da razão no ensino e a pesquisa em administração na concepção da teoria crítica. Revista de Ciências da Administração, 18(45), 140-154.

Fischer, C. M., \& Amabile, T. M. (2009). Creativity, improvisation and organizations. In T. Rickards, M. A. Runco, M. A., \& S. Moger (Eds.), The Routledge Companion to Creativity. New York, NY: Routledge.

Fisher, C. M., \& Barrett, F. (2017). The Experience of Improvising in Organizations: A Creative Process Perspective. Academy of Management Perspectives, 33(2),148-162

Fisher, T., Waiandt, C., \& Fonseca, R. L. (2011). A História do Ensino em Administração: Contribuições Teórico-Metodológicas e uma Proposta de Agenda de Pesquisa. Revista de Administração Pública, 45(4), 911-939.

Flach, L. (2010). Improvisação e aprendizagem em cervejarias artesanais: um estudo no Brasil e na Alemanha (Tese de Doutorado). Programa de Pós-Graduação em Administração, Universidade Federal do Rio Grande do Sul, Porto Alegre, RS.

Flach, L. (2012). A Rota das Cervejarias Artesanais de Santa Catarina: Analisando Improvisação e Aprendizagem. GESTÃO.Org, 10(3), 567-594.

Flach, L., \& Antonello, C. S. (2011). Improvisação e Aprendizagem nas Organizações: reflexões a partir da metáfora da improvisação no teatro e na música. In C. S. Antonello, \& A. S. Godoy (Eds.), Aprendizagem Organizacional no Brasil. Porto Alegre, RS: Bookman.
Flach, L., \& Antonello, C. S. (2011). Improvisation and Learning Processes in Organizations: A Metaphor Applying the Brazilian Rhythm Choro. Organizações \& Sociedade, 18(59), 681-699.

Freire, P. (2005). Pedagogia do Oprimido. Rio de Janeiro, RJ: Paz e Terra.

Gagliardi, P., \& Czarniawska, B. (2006). Management education and humanities. Cheltenham, UK: Edward Elgared.

Giustiniano, L., Cunha, M. P., \& Clegg, S. (2016). LEGG, S. The dark side of organizational improvisation: Lessons from the sinking of Costa Concordia. Business Horizons, 59(2), 223-232.

Grisoni, L., \& Kirk, P. (2006). Verse, voice and va va voom! illuminating management processes through poetry. Management Decision, 44(4), 512-525.

Hallam, E., \& Ingold, T. (2007). Creativity and cultural improvisation. New York, NY: Berged.

Hardy, C., \& Phillips, N. (1999). No joking matter: Discursive struggle in the Canadian refugee system. Organization Studies, 20(1), 1-24.

Hatch, M. J. (2002). Explorando os Espaços Vazios: Jazz e Estrutura Organizacional. Revista de Administração de Empresas, 42(3), 19-35.

Hatch, M. J. (1999). Exploring the Empty Spaces of Organizing: How Improvisational Jazz Helps Redescribe Organizational Structure. Organization Studies, 20(1), 75-100.

Hatch, M. J. (1998). Jazz as a Metaphor for Organizing in the $21^{\text {st }}$ century. Organization Science, 9(5), 556-557.

Hatch, M. J. (1997). Jazzing up the Theory of Organizational Improvisation. Advances in Strategic Management, 14, 181-191.

Hatch, M. J. (2002). Explorando os Espaços Vazios: Jazz e Estrutura Organizacional. Revista de Administração de Empresas, 42(3), 19-35.

Hmieleski, K. M., \& Corbett, A. C. (2006). Proclivity for Improvisation as a Predictor of Entrepreneurial Intentions. Journal of Small Business Management, 44(1), 45-63.

Hmieleski, K. M., \& Corbett, A. C. (2008). The contrasting interaction effects of improvisational behavior with entrepreneurial self-efficacy on new venture performance and entrepreneur work satisfaction. Journal of Business Venturing, 23(4), 482-496.

Kamoche, K. N., \& Cunha, M. P. (2001). Minimal structures: from jazz imrprovisation to product innovation. Organization Studies, 22(5), 733-764

Kamoche, K. N., Cunha, M. P., \& Cunha, J. V. (2002). Organizational Improvisation. New York, NY: Routledge.

Kamoche, K. N., Cunha, M. P., \& Cunha, J. V. (2003). Towards a theory of organizational improvisation: looking beyond the jazz metaphor. Journal of Management Studies, 40(8), 2023-2051.

Kirschbaum, C., Sakamoto, C., \& Vasconcelos, F. C. (2014). Conflito e improvisação por design: a metáfora do repente. Organizações \& Sociedade, 21(68), 59-78.

Koppett, K. (2013). Training to imagine: practical improvisational theatre techniques for trainers and managers to enhance creativity, teamwork, leadership, and learning. Sterling, VA: Stylus Publishing.

Landfaster, U., \& Metelmann, J. (2019). Transformative Management Education. London, UK: Routledge. 
Lewin, A. Y. (1998). Jazz improvisation as a metaphor for organization theory. Organization Science, 9(5), 539.

Leybourne, S. A. (2006). Managing Improvisation within Change Management: Lessons from UK Financial Services. The Service Industries Journal, 26(1), 73-95.

Leybourne, S. A. (2009). Improvisation and Agile Project Management: A Comparative Consideration. International Journal of Managing Projects in Business, 2(4), 519-535.

Leybourne, S. A., \& Sadler-Smith, E. (2006). The Role of Intuition and Improvisation in Project Management. International Journal of Project Management, 24, 483-492.

Lima, T., \& Silva, A. (2017). O Ambiente Estrutural e Institucional do Ensino de Administração na Região Nordeste do Brasil. Administração: Ensino e Pesquisa, 18(2), 231-269.

Mannucci, P. V., Orazi, D. C., \& Valck, K. (2020). Developing Improvisation Skills: The Influence of Individual Orientations. Administrative Science Quarterly, 50, 329-366.

March, J., \& Weil, T. (2005). On Leadership. New York, NY: Blackwell Publishing.

Miner, A. S., Bassoff, P., \& Moorman, C. (2001). Organizationa Improvisation and Learning: A Field Study. Administrative Science Quarterly, 46(2), 304-337.

Mintzberg, H., \& Gosling, J. (2003). Educando administradores além das fronteiras. Revista de Administração de Empresas, 43(2), 29-43.

Montuori, A. (2003). The Complexity of Improvisation and the Improvisation of Complexity: Social Science, Art and Creativity. Human Relations, 56(2), 237.

Moorman, C., \& Miner, A. S. (1998). Organizational Improvisation and Organizational Memory. Academy of Management Review, 23(4), 698-723.

Moorman, C., \& Miner, A. S. (1998). The Convergence of Planning and Execution: Improvisation in New Product Development. Journal of Marketing, 62(3), 1-20.

Neck, H., Neck, C., \& Murray, E. (2018). Entrepreneurship: The Practice and Mindset. London, UK: Sage Publications.

Nicholls, T. (2012). An Ethics of Improvisation: Aesthetic Possibilities for a Political Future. Lanham, Maryland: Lexington Books.

Nunes, S. C. (2010). O Ensino em Administração: Análise à Luz da Abordagem das Competências. Revista de Ciências da Administração, 12(28), 198-223.

Oliveira, A. L., Lourenço, C. D. S., \& Castro, C. C. (2015). Ensino de Administração nos EUA e no Brasil: uma análise histórica. Pretexto, 16(1), 11-22.

Orlikowski, W. J. (1996). Improvising Organizational Transformation Over Time: A Situated Change Perspective. Information Systems Research, 7(1). Recuperado de https://doi.org/10.1287/isre.7.1.63

Orlikowski, W. J. (2000). Using Technology and Constituting Structures: A Practice Lens for Studying Technology in Organizations. Organization Science, 12(4), 404-428.
Orlikowski, W. J., \& Hofman, J. D. (1997). An improvisational model for change management: the case of groupware technologies. Sloan Management Review, Winter, 11-21.

Paiva, K. C. M., Esther, A. B., \& Melo, M. C. O. L. O. (2004). Formação de Competências e Interdisciplinaridade no Ensino de Administração: uma visão dos alunos. Revista Gestão e Planejamento, 5(10), 63-77.

Patient, D., Lawrence, T., \& Maitlis, S. (2003). Understanding workplace envy through narrative fiction. Organization Studies, 24(7), 1015-1044.

Raelin, J. (2007). Toward na Epistemology of Practice. Academy of Management Learning \& Education, 6(4), 495-519.

Ratten, V., \& Hodge, J. (2016). So much theory, so little practice: a literature review of workplace improvisation training. Industrial and Commercial Training, 48(3), 149-155.

Sawyer, R. K. (2000). Improvisation and the Creative Process: Dewey, Collingwood, and the aesthetics of spontaneity. The Journal of Aesthetics and Art Criticism, 58(2), 149-161.

Sawyer, R. K. (2000). Improvisational cultures: collaborative emergence and creativity in improvisation. Mind, Culture and Activity, 7(3), 180-185.

Scharmer, O. (2010). Teoria U: Como liderar pela percepção e realização do futuro emergente. Rio de Janeiro, RJ: Editora Campus.

Schon, D. (1983). The reflective practitioner: how professional think in action. New York, NY: Basic Books.

Shaw, P., \& Stacey, R. (2006). Experiencing Spontaneity, Risk \& Improvisation in Organizational Life: Working Live. London, UK: Routledge.

Silva, J. R. G. (2000). Significado da Mudança: as percepções dos funcionários de uma empresa brasileira diante da expectativa de privatização. Revista de Administração Pública, 34(1), 79-99.

Silva, J. R. G., \& Vergara, S. C. (2002). Análise comparativa acerca da utilização de desenhos na pesquisa sobre a criação do sentido da mudança organizacional. Organizações \& Sociedade, 9(23), 1-20.

Sorensen, B. M. (2014). Changing the Memory of Suffering: An Organizational Aesthetics of the Dark Side. Organization Studies, 35(2), 279-302.

Steyaert, C., Beyes, T., \& Parker, M. (2016). The Routledge Companion to Reinventing Management Education. New York, NY: Routledge.

Sullivan, G. (2010). Art Practice as Research. Los Angeles, CA: Sage Publication.

Tabesh, P., \& Vera, D. M. (2020). Top managers improvisational decision-making in crisis: A Paradox Perspective. Management Decision, 58(10), 2235-2256.

Vera, D., \& Crossan, M. (2005). Improvisation and innovative performance in teams. Organisation Science, 16(3), 203-224.

Vera, D., \& Crossan, M. (2004). Theatrical Improvisation: Lessons for Organizations. Organization Studies, 25(5), 727-749.

Vergara, S. (2003). Repensando a relação ensino-aprendizagem em Administração: Argumentos Teóricos, Práticas e Recursos. Organizações \& Sociedade, 10(28), 131-142. 
Wankel, C., \& DeFillippi, R. (2006). New Visions of Graduate Management

Education. Charlotte, North Carolina: Information Age Publishing.

Weick, K. E. (1989). Organized improvisation: 20 years of organizing. Communication Studies, 40(4), 241-248.

Weick, K. E. (1993). The collapse of sensemaking in organizations: The Mann Gulch disaster. Administrative Science Quarterly, 38(4), 628-652.
Weick, K. E. (1998). Introductory essay-improvisation as a mindset for organizational analysis. Organization Science, 9(5), 539-622.

Weick, K. E. (2002). A estética da imperfeiçao em orquestras e organizaçoes. Revista de Administração de Empresas, 42(3), 6-18.

Young, J. O. (2001). Art and knowledge. London, UK: Routledge.

Zack, M. H. (2000). Jazz improvisation and organizing: once more from the top. Organization Science, 11(2), 227-234.

Ph.D. em Administração pela École des Hautes Études commerciales de Montreal (HEC Montréal), com pós-doutorado em Administração pela Nova School of Business and Economics da Universidade Nova de Lisboa; Professor na Escola de Administração da Universidade Federal da Bahia (EAUFBA)

E-mail: davel.eduardo@gmail.com 